\title{
Comparison of Arthroscopic, Radioactive and Combined Synovectomy in the Treatment of Chronic Non-Specific Knee Synovitis
}

\author{
Ibrahim Karaman ${ }^{\mathrm{a}}$ Ahmet Guney ${ }^{\mathrm{a}}$ Fatih Dogar ${ }^{\mathrm{c}}$ Ibrahim Halil Kafadar ${ }^{\mathrm{a}}$

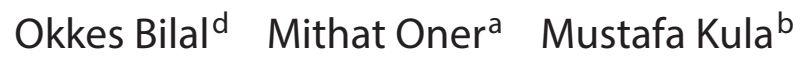 \\ Departments of ${ }^{\mathrm{a}}$ Orthopaedics and Traumatology and ${ }^{\mathrm{b}}$ Nuclear Medicine, Erciyes University Medical Faculty, and \\ 'Training and Research Hospital, Kayseri, and d Sütcü Imam University Medical Faculty, Kahramanmaraş, Turkey
}

\section{Key Words}

Chronic effusion · Synovectomy · Radiosynoviorthesis ·

Arthroscopy $\cdot$ Yttrium

\begin{abstract}
Objective: To compare the outcomes of arthroscopic, radioactive and combined synovectomies in patients with chronic non-specific recurrent synovitis who did not respond to conservative therapy. Subjects and Methods: Twenty-nine patients enrolled between 2007 and 2011 were divided into 3 groups: group 1 was treated with arthroscopy, group 2 received a radioactive drug and group 3 received a combined (radioactive and arthroscopic) synovectomy. Treatment efficacy was evaluated by comparing pre- and post-operative Lysholm knee scores (LKS), night pain, resting pain, activity pain and effusions using visual analogue scales (VAS). Patient satisfaction was assessed using the visual analogue patient satisfaction scale (VAPSS). Results: The mean age of the study participants was $41.5 \pm 5.2$ years (range 14-76), and the mean follow-up period was $33.6 \pm 3.2$ months (range 17-78). Before treatment, the mean LKS was $41.4 \pm 3.4$ in group 1, 39.6 \pm 3.3 in group 2 and $37.1 \pm 4.6$ in group 3. After treatment, the corresponding mean LKS were $77.7 \pm 2.1$,
\end{abstract}

$81.6 \pm 2.8$ and $91.3 \pm 2.7$ in groups 1,2 and 3, respectively; the increase was statistically significant $(p<0.05)$. The VAS scores before and after treatment decreased significantly $(p<0.05)$. The mean VAPSS score, a measure of patient satisfaction, was $5.1 \pm 1.7,5.8 \pm 1.5$ and $7.4 \pm 1.8$ in groups 1,2 and 3, respectively, and the difference between groups 1 and 2 was not statistically significant, while that between group 3 and the other two groups was significant $(p<0.05)$. Conclusion: This study showed that the three methods used in individuals with chronic non-specific recurrent synovitis were effective; however, arthroscopic synovectomy in combination with radioactive synovectomy was more effective than the other methods and superior in terms of patient satisfaction.

(c) 2014 S. Karger AG, Basel

\section{Introduction}

Chronic non-specific synovitis is a recurrent, proliferative synovial lesion which often involves a single joint. The main symptoms are pain and swelling, which lead to dysfunction of the joint. Chronic non-specific synovitis is the most common type of arthritis [1].

\begin{tabular}{ll}
\hline KARGER & $\begin{array}{l}\text { ( ) 2014 S. Karger AG, Basel } \\
1011-7571 / 14 / 0236-0551 \$ 39.50 / 0 \quad \text { Karger }\end{array}$ \\
$\begin{array}{l}\text { E-Mail karger@karger.com } \\
\text { www.karger.com/mpp }\end{array}$ & $\begin{array}{l}\text { Thisis an Open Access article licensed under the terms of the } \\
\text { Creative Commons Attribution-NonCommercial 3.0 Un- } \\
\text { ported license (CC BY-NC) (www.karger.com/OA-license), } \\
\text { applicable to the online version of the article only. Distribu- } \\
\text { tion permitted for non-commercial purposes only. }\end{array}$
\end{tabular}

Dr. Ibrahim Karaman

Erciyes University, Gevher Nesibe Hospital

Talas street

TR-38039 Kayseri (Turkey)

E-Mail drikaraman@gmail.com 
Among individuals with synovitis, the incidence of chronic non-specific synovitis ranges from 47 to $71 \%$ [2]. A definitive diagnosis is made based on histopathologic findings [2]. The main goals of synovectomy are to relieve the symptoms that cause discomfort in the patient, protect the joint cartilage and prevent the development of chronic synovitis [3]. The surgical options for chronic non-specific synovitis are arthroscopic synovectomy (AS) and open synovectomy. The most important disadvantage of open synovectomy is the occurrence of adhesions caused by the wide dissection, leading to postoperative limitations of motion caused by scar tissue. Currently, AS is a more widely used technique because of the absence of arthrotomy, post-operative muscle atrophy, limitation of motion, and blood loss, as well as less prevalent pain and fewer hospital recovery days [4]. However, the recurrence rate of synovitis has been reported to be higher in patients treated with arthroscopy because of insufficient removal of the inflamed synovial membrane [4]. Radioactive synovectomy (RS) is another method used to treat recurrent synovitis, and RS can hold down the inflammatory stimulus $[5,6]$. The yttrium-90 (Y-90) colloid, which is able to penetrate deeply into tissue, is an appropriate radionuclide for the knee joint and those with substantially thickened synovia [5]. RS is most commonly used in the treatment of rheumatoid arthritis (RA), osteoarthritis, pigmented villonodular synovitis and haemophilic arthropathy [7-10]. The aim of this study was to compare the outcomes of arthroscopic, radioactive and combined arthroscopic and RS in patients with chronic nonspecific synovitis who did not respond to conservative therapy.

\section{Subjects and Methods}

This study was approved by the Ethics Committee of Erciyes University. All of the patients provided written informed consent before participation. The medical records of the patients at the Department of Orthopaedics and Traumatology of the Erciyes University Medical Faculty from April 2007 to August 2012 were reviewed. Patients who had chronic non-specific recurrent synovitis of the knee despite 6 months of conservative therapy consisting of rest, non-steroidal anti-inflammatory drugs and intra-articular steroid injection and who underwent synovectomy were divided into the following groups: group 1 : AS $(n=10)$, group 2: RS $(n=9)$ and group 3: combined synovectomy $(n=$ 10). Group 3 comprised patients who had previously received arthroscopic intervention and continued to complain of postoperative effusion. RS was performed on these patients in addition to arthroscopic intervention because of an increase in activity observed via scintigraphy 6 weeks after synovectomy. Exclusion criteria were patients with other aetiologies of synovitis such as RA, spondyloarthropathy, infectious arthritis, osteoarthritis, pigmented villonodular synovitis and haemophilic arthropathies and also patients with knee instability, meniscal pathology and chondral lesions that could induce synovitis. All of the patients were observed to have synovial hypertrophy and increased synovial fluid on MRI. At the same time, there were no meniscal, ligamentous or chondral lesions, which could induce synovitis. Knees (right, $\mathrm{n}=16$; left, $\mathrm{n}=13$ ) from 29 patients (11 females and 18 males) were included in this study. In all groups, the Lysholm knee score (LKS) and night pain $(0-10)$, resting pain $(0-10)$, activity pain $(0-10)$ and effusions $(0-3)$ were assessed before and after treatment using visual analogue scales (VAS). Patient satisfaction was assessed using the visual analogue patient satisfaction scale (VAPSS). Magnetic resonance imaging (MRI) was performed on all patients before the initiation of treatment.

\section{Arthroscopic Synovectomy}

Arthroscopy was performed by the same surgeon (A.G.) using general or spinal/epidural anaesthesia. The surgeon used a pneumatic tourniquet via the anterolateral and anteromedial portals, and if needed the superolateral or superomedial portals were used. A synovial biopsy was performed during the arthroscopy to confirm the diagnosis. Synovial tissues with an inflamed appearance were removed using an arthroscopic shaver. After completion of the synovectomy, the tourniquet was released and homeostasis was achieved using arthroscopic cautery. After repeated flushing from the available portals, a drain was placed via the anteromedial portal and a compressive bandage was applied. A 20-min cold treatment was applied every $2 \mathrm{~h}$ during the first $24 \mathrm{~h}$. The drains were removed $24 \mathrm{~h}$ after the surgery and exercises were initiated using a continuous passive motion exercise device.

\section{Radioactive Synovectomy}

RS was performed in a sterile manner in the operating room 6 weeks after synovectomy for group 3 and the confirmation of synovitis by MRI and scintigraphy for group 2 . After cleansing the knee with an antiseptic solution, an 18-gauge needle was inserted into the joint. Placement was confirmed by washing with $1-2 \mathrm{ml}$ of normal saline, and the joint fluid was evacuated. Then, $5 \mathrm{mCi}$ (185 MBq) of a Y-90 colloid suspension (IBA Molecular, CIS Bio International, France) was injected into the joint. To prevent radionuclide accumulation within the needle, 1-2 ml of normal saline was injected and the needle was then removed. The joint was passively moved to achieve a homogenous distribution. A long leg splint was applied to the knee to prevent the leakage of radionuclide, and $48-72 \mathrm{~h}$ of rest was provided. A scintigraphy was performed $24 \mathrm{~h}$ after the RS to assess for the presence of radionuclide leakage.

\section{Statistical Analysis}

SPSS for Windows version 15.0 software (SPSS Inc., Chicago, Ill., USA) was used for statistical analysis. The Kruskal-Wallis test was used to compare numerical variables between groups, and the Wilcoxon signed-rank test was used to compare the values obtained before and after the intervention. The $\chi^{2}$ test was used to compare qualitative variables. $p<0.05$ was considered statistically significant. 
Table 1. VAS scores for pre- and post-treatment night pain, rest pain, activity pain, effusion, and LKS in the three study groups

\begin{tabular}{|c|c|c|c|c|c|c|}
\hline & \multicolumn{2}{|c|}{ Group 1 (arthroscopic synovectomy) } & \multicolumn{2}{|c|}{ Group 2 (radioactive synovectomy) } & \multicolumn{2}{|c|}{ Group 3 (combined synovectomy) } \\
\hline & pre-treatment & post-treatment & pre-treatment & post-treatment & pre-treatment & post-treatment \\
\hline LKS & $41.4 \pm 3.4$ & $77.7 \pm 2.1$ & $39.6 \pm 3.3$ & $81.6 \pm 2.8$ & $37.1 \pm 4.6$ & $91.3 \pm 2.7$ \\
\hline Night pain VAS & $8.6 \pm 0.4$ & $2.9 \pm 0.3$ & $9.1 \pm 0.3$ & $2.5 \pm 0.2$ & $9.2 \pm 0.2$ & $2.1 \pm 0.4$ \\
\hline Rest pain VAS & $7.5 \pm 0.4$ & $2.1 \pm 0.2$ & $8.1 \pm 0.4$ & $1.2 \pm 0.3$ & $8.2 \pm 0.3$ & $1.4 \pm 0.4$ \\
\hline Activity pain VAS & $8.8 \pm 0.3$ & $3.7 \pm 0.3$ & $9.3 \pm 0.2$ & $2.5 \pm 0.3$ & $9.8 \pm 0.2$ & $2.2 \pm 0.4$ \\
\hline Effusion VAS & $2.6 \pm 0.2$ & $0.8 \pm 0.2$ & $3.0 \pm 0.2$ & $0.5 \pm 0.1$ & $3 \pm 0.4$ & $0.4 \pm 0.2$ \\
\hline
\end{tabular}

Values are presented as means \pm SD. $\mathrm{p}<0.05$
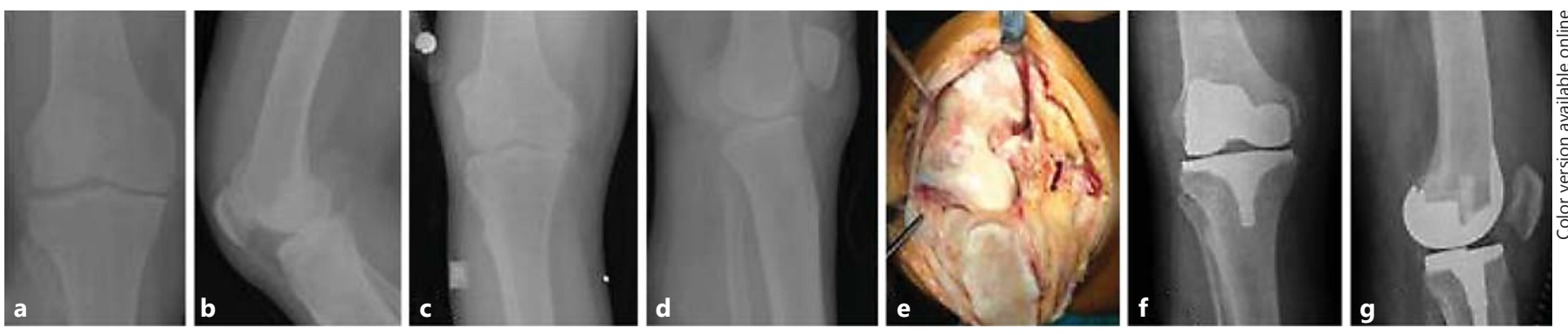

Fig. 1. Patient who developed degenerative osteoarthritis after combined treatment. a, b Baseline anteroposterior and lateral radiographs before combined treatment. c, $\mathbf{d}$ Anteroposterior and lateral radiographs after combined treatment. e Appearance of the intraoperative cartilage damage. $\mathbf{f}, \mathbf{g}$ Appearance after total knee arthroplasty.

\section{Results}

The mean age was $41.5 \pm 5.2$ years (range 14-76), and the mean follow-up period was $33.6 \pm 3.2$ months (range 17-78). The mean LKS was $41.4 \pm 3.4$ in group 1, $39.6 \pm$ 3.3 in group 2 and $37.1 \pm 4.6$ in group 3 before treatment, which significantly increased after treatment to $77.7 \pm 2.1$ in group $1,81.6 \pm 2.8$ in group 2 and $91.3 \pm 2.7$ in group 3 ( $<<0.05)$. The VAS scores for night pain, rest pain, activity pain and effusion decreased significantly after treatment in all groups $(\mathrm{p}<0.05$; table 1$)$. The mean VAPSS values after treatment were $5.1 \pm 1.7,5.8 \pm 1.5$ and $7.4 \pm$ 1.8 in groups 1, 2 and 3, respectively.

Histopathologic evaluation of the synovial biopsy samples showed papillary hyperplasia and subsynovial lymphocytic infiltration, which was pathognomonic for chronic non-specific synovitis. No radionuclide leakage or complications such as haematomas, infections, arthrofibrosis, skin necrosis or hypersensitivity were detected in any of the patients by post-treatment scintigraphy and evaluation. Only 1 patient in group 3 underwent total

Arthroscopic, Radioactive and Combined Synovectomy knee arthroplasty 14 months after the surgery because of the development of severe degenerative osteoarthritis (fig. 1).

\section{Discussion}

In this study, we showed that AS, RS and combined interventions were performed in patients with chronic synovitis. However, combined treatment was found to be more effective than the other two methods. Also, we concluded that combined treatment had a greater VAPPS in the early follow-up period in terms of patient satisfaction.

Synovitis is commonly encountered among patients presenting with knee complaints. In cases of chronic nonspecific synovitis, surgery involving RS should be performed in those who have derived no benefit from conservative therapy. In patients with synovitis, the incidence of chronic non-specific synovitis ranged from 47 to $71 \%$ in different studies [2]. Synovitis is the main factor in the cartilage degeneration that leads to osteoarthritis [11]. 
In recent years, AS has begun to replace open synovectomy because of its benefits $[12,13]$. However, the recurrence rate of synovitis has been reported to be higher in a group treated with arthroscopy rather than open surgery. The reason for the high recurrence rate is the insufficient removal of the synovial membrane [14]. After the AS, the long-term recurrence rate was $29.3 \%$ according to Roch-Bras et al. [4]. Since AS has a higher recurrence rate, we also used a combined treatment method. There was no recurrence of synovitis during the follow-up of the study.

Klug et al. [15] performed AS on 93 knees of 81 patients with RA and reported good or very good outcomes in $76.4 \%$ of patients after a mean follow-up of 33 months. Gibbons et al. [16] reported that joint movements could be protected or improved in $73 \%$ of 25 knees after at least 6 years of follow-up after AS was performed because of RA. The authors also reported that arthroplasty was needed in only 2 patients, though radiologic progression of the arthritis was observed in all patients [16]. On the other hand, Matsui et al. [17] and Oztemür et al. [18] compared AS with open synovectomy. There was no significant difference between the open synovectomy and AS groups in terms of outcomes. We preferred AS because there it involves less muscle atrophy, minimal loss of range of motion, a shorter hospitalization period, early recovery, little pain and excellent cosmetic results, and the radiologic outcomes are better after long-term follow-up compared to open synovectomy. However, to the best of our knowledge, there is no study in the current literature comparing non-specific synovitis AS, RS and combined synovectomy in the same study.

Reportedly, the agent used in RS should exhibit radiation energy with a penetration sufficient to cause ablation in the synovial tissue, but not to the extent that it causes necrosis in the cartilage or skin. The radionuclide dose should be small enough to be phagocytosed, and it should be given in amounts that are limited enough so that leakage does not occur from the joint [19]. $\beta$-Emitting radionuclide agents are generally used for RS. In knee joints, Y-90 is preferred in doses of 5-15 $\mathrm{mCi}$ [19]. In our patients, a low dose of $5 \mathrm{mCi}$ was preferred because of the good penetration profile of Y-90 and our cohort's lack of patients with a higher recurrence risk, such as those with RA. Kresnik et al. [20] authored a meta-analysis of 2,190 joints treated with RS and noted that patients with RA experienced better success rates than those with osteoarthritis. Additionally, Kampen et al. [11] stated that the best clinical results were obtained in patients with RA.
Because of the good penetration and low adverse effect profile in this study, we used Y-90 for the RS, in accordance with the literature.

When AS is performed alone, it is impossible to access the entire knee and remove all of the inflamed tissue, especially in the posterolateral and posteromedial compartments. This may be the reason for the higher recurrence rate after AS compared to open synovectomy. The combination of AS with RS appears to be a reliable treatment modality for the removal of residual synovial tissues after AS [21, 22]. Jacob et al. [23] performed RS using Y-90 in 28 patients (38 joints) with chronic arthritis. The authors demonstrated that, of 34 joints, the outcome was poor in 6 , good in 2 and satisfactory in the remaining 26 joints after more than 3 years of follow-up. Kerschbaumer et al. [22] and Goetz et al. [24] reported the advantages of combined treatment in their studies, in which AS, AS combined with RS and RS alone were compared in synovitis caused by RA. For this reason, we performed combined synovectomy in this study. In our study, after treatment, the highest increase in LKS and the greatest decrease in VAS scores were seen in the combined group. Also, the VAPSS scores were higher in the combined group than in the other two groups.

Reportedly, complications such as radionecrosis develop in some patients after RS $[25,26]$. In our study, severe degenerative osteoarthritis developed as a complication in only 1 patient who was in the combined-treatment group, and the patient underwent total knee arthroplasty 14 months after the combined treatment. We found no radionuclide leakage on control scintigraphies. No adverse events, such as allergic reaction, skin necrosis or pigmentation or fever, were observed.

The limitations of this study include the low number of patients, the short length of follow-up and its retrospective nature. Thus, a prospective study with a longer length of follow-up and more patients should be planned.

\section{Conclusion}

This study showed that all three interventions (AS, RS and combined) performed in patients with chronic synovitis were effective; however, AS in combination with RS was more effective than the other methods and achieved greater patient satisfaction in the early follow-up period. Additionally, continued follow-up of these patients is planned to evaluate the long-term results. 


\section{References}

1 Dabov G, Perez EA: Miscellaneous nontraumatic disorders; in Canale ST (ed): Campbell's Operative Orthopaedics, ed 10. Philadelphia, Mosby, 2003, pp 905-906.

2 Vijay PM, Doddikoppad MM: Clinicopathological study of inflammatory synovial lesions. Int J Biol Med Res 2011;2:882-888.

$>3$ Al-Jarallah K, Shehab D, Moussa MAA, et al: Validation of the Arabic version of the early inflammatory arthritis detection tool. Med Princ Pract 2013;22:449-452.

$\checkmark 4$ Roch-Bras F, Daures JP, Legouffe MC, et al: Treatment of chronic knee synovitis with arthroscopic synovectomy: long term results. J Rheumatol 2002;29:1171-1175.

$\checkmark 5$ Fellinger K, Schmid H: Local therapy of rheumatic diseases (in German). Wien Z Inn Med 1952;33:351-363.

-6 Zuderman L, Liepe K, Zophel K, et al: Radiosynoviorthesis (RSO): influencing factors and therapy monitoring. Ann Nucl Med 2008;22: 735-741.

$\checkmark 7$ Chrapko B, Zwolak R, Nocuń A, et al: Radiation synovectomy with ${ }^{90} \mathrm{Y}$ colloid in the therapy of recurrent knee joint effusions in patients with inflammatory joint diseases. Rheumatol Int 2007;27:729-734.

8 Chatzopoulos D, Moralidis E, Markou P, et al: Yttrium-90 radiation synovectomy in knee osteoarthritis: a prospective assessment at 6 and 12 months. Nucl Med Commun 2009;30: 472-479.

$>9$ Shabat S, Kollender Y, Merimsky O, et al: The use of surgery and ${ }^{90} \mathrm{Y}$ in the management of extensive and diffuse pigmented villonodular synovitis of large joints. Rheumatology 2002; 41:1113-1118.
10 Kavakli K, Aydoğdu S, Omay SB, et al: Longterm evaluation of radioisotope synovectomy with ${ }^{90} \mathrm{Y}$ for chronic synovitis in Turkish haemophiliacs: Izmir experience. Haemophilia 2006;12:28-35.

11 Kampen WU, Brenner W, Kroeger S, et al: Long-term results of radiation synovectomy: a clinical follow-up study. Nucl Med Commun 2001;22:239-246.

12 Maslon A, Witoński D, Pieszyński I, et al: Early clinical results of open and arthroscopic synovectomy in knee inflammation. Ortop Traumatol Rehabil 2007;9:520-526.

13 Dell'Era L, Facchini R, Corona F: Knee synovectomy in children with juvenile idiopathic arthritis. J Pediatr Orthop B 2008;17:128-130.

14 Blahut J: Synovectomy of the knee joint. Acta Chir Orthop Traumatol Cech 2003;70:371376.

15 Klug S, Wittmann G, Weseloh G: Arthroscopic synovectomy of the knee joint in early cases of rheumatoid arthritis: follow-up results of a multicenter study. Arthroscopy 2000;16:262267.

16 Gibbons CE, Gosal HS, Bartlett J: Long-term results of arthroscopic synovectomy for seropositive rheumatoid arthritis: 6-16 year review. Int Orthop 2002;26:98-100.

17 Matsui N, Moriya H, Kitahara H: Arthroscopic versus open synovectomy in the rheumatoid knee. Int Orthop 1989;13:17-20.
18 Oztemür Z, Bulut O, Korkmaz M, et al: Surgical synovectomy combined with yttrium 90 in patients with recurrent joint synovitis. Rheumatol Int 2013;33:1321-1326.

19 Schneider P, Farahati J, Reiners C: Radiosynovectomy in rheumatology, orthopedics, and hemophilia. J Nucl Med 2005;46:48S-54S.

20 Kresnik E, Mikosch P, Gallowitsch HJ, et al: Clinical outcome of radiosynoviorthesis: a meta-analysis including 2,190 treated joints. Nucl Med Commun 2002;23:683-688.

21 Akmeşe R, Yildiz KI, Işik C, et al: Combined arthroscopic synovectomy and radiosynoviorthesis in the treatment of chronic non-specific synovitis of the knee. Arch Orthop Trauma Surg 2013;133:1567-1573.

-22 Kerschbaumer F, Kandzioar F, Herresthal J, et al: Combined arthroscopic and radiation synovectomy in rheumatoid arthritis. Orthopade 1998;27:188-196.

23 Jacob R, Smith T, Prakasha B, et al: Yttrium synovectomy in the management of chronic knee arthrithis: a single experience. Rheumatol Int 2003;23:216-220.

24 Goetz M, Klug S, Gelse K, et al: Combined arthroscopic and radiation synovectomy of the knee joint in rheumatoid arthritis: 14-year follow-up. Arthroscopy 2011;27:52-59.

25 Bickels J, Isaakov J, Kollender Y, et al: Unacceptable complications following intra articular injection of yttrium ${ }^{90}$ in the ankle joint for diffuse pigmented villonodular synovitis. J Bone Joint Surg Am 2008;90:326-328.

26 Kavakli K, Cogulu O, Aydogdu S, et al: Longterm evaluation of chromosomal breakages after radioisotope synovectomy for treatment of target joints in patients with haemophilia. Haemophilia 2010;16:474-478. 